Research Paper

\title{
Effects of Satureja Bachtiarica Essential Oil in Preventing Seizure in Pentylenetetrazol-Kindled Mice
}

\author{
Zahra Rabiei $^{1}$ (D), Manouchehr Shirchi ${ }^{1}$ (D), Mahmoud Rafieian-Kopaei ${ }^{1 *}$ (D), Samira Asgharzade Ma $^{2,3}$ (D) \\ 1. Medical Plants Research Center, Basic Health Sciences Institute, Shahrekord University of Medical Sciences, Shahrekord, Iran. \\ 2. Cellular and Molecular Research Center, Basic Health Sciences Institute, Shahrekord University of Medical Sciences, Shahrekord, Iran. \\ 3. Department of Molecular Medicine, School of Advanced Technologies, Shahrekord University of Medical Sciences, Shahrekord, Iran.
}

\begin{tabular}{|c|c|}
\hline $\begin{array}{l}\text { Use yourdevice toscan } \\
\text { and read the article online }\end{array}$ & Citation Rabiei, Z., Shirchi, M., Rafieian-Kopaei, M., and Asgharzade, S. Effects of Satureja Bachtiarica Essential \\
\hline 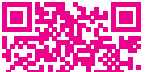 & $\begin{array}{l}\text { Oil in Preventing Seizure in Pentylenetetrazol-Kindled Mice. Basic and Clinical Neuroscience, 13(4), 465-476. http:// } \\
\text { dx.doi.org/10.32598/bcn.2021.1665.1 }\end{array}$ \\
\hline artan & dol'http://dx.doi.org/10.32598/bcn.2021.1665.1 \\
\hline
\end{tabular}

Article info:

Received: 05 Jan 2019

First Revision: 08 Feb 2020

Accepted: 11 Oct 2020

Available Online: $01 \mathrm{Jul} 2022$

Keywords:

Satureja bachtiarica, epilepsy, GABAergic activity, PTZ-kindled

\begin{abstract}
AB S TRACT
Introduction: Epilepsy is a group of chronic neurological disorders characterized by seizures. The present study aimed to investigate the effects of Satureja bachtiarica essential oil in preventing epilepsy.

Methods: In this experimental study, 50 mice were randomly assigned to five groups of 10 each. The control group received normal saline plus tween- 80 and after 30 min pentylenetetrazol (PTZ). Groups 2 and 3 were treated first with $S$. bachtiarica essential oil at 50 and $100 \mathrm{mg} / \mathrm{kg}$, respectively and then after $30 \mathrm{~min}$ received PTZ. Group 4 received diazepam and $30 \mathrm{~min}$ later PTZ. Group 5 received flumazenil and $30 \mathrm{~min}$ later PTZ. After the last injection of PTZ, the time of seizure onset, seizure severity and score, the completion time of each seizure (attack episode), and mortality rate in different groups were recorded and compared.

Results: The administration of $S$. bachtiarica essential oil at 50 and $100 \mathrm{mg} / \mathrm{kg}$ to PTZtreated mice caused a significant increase in latency to the first seizure and survival of mice, as well as a significant decrease in the frequency of the head and upper limbs seizure, total body seizures, tonic seizures, and jumping. S. bachtiarica essential oil at $100 \mathrm{mg} / \mathrm{kg}$ caused a significant decrease in the head tic frequency. The administration of flumazenil significantly inhibited $S$. bachtiarica essential oil-induced effects and increased the head and upper limbs seizures, tonic seizures, and jumping.

Conclusion: The present study demonstrated that $S$. bachtiarica essential oil could prevent PTZ-induced seizure and these findings authenticate the traditional claims about the use of $S$. bachtiarica in treating epilepsy.
\end{abstract}

\footnotetext{
* Corresponding Author:

Mahmoud Rafieian-Kopaei, PhD.

Address: Medical Plants Research Center, Basic Health Sciences Institute, Shahrekord University of Medical Sciences, Shahrekord, Iran Tel: +98 (381) 3346692

E-mail:rafeian@yahoo.com
} 


\section{Highlights}

- The administration of $S$. bachtiarica essential oil at 50 and $100 \mathrm{mg} / \mathrm{kg}$ to pentylenetetrazol PTZ-treated mice caused a significant increase in latency to the first seizure.

- The administration of $S$. bachtiarica essential oil at 50 and $100 \mathrm{mg} / \mathrm{kg}$ to PTZ-treated mice caused a significant decrease in the frequency of the head and upper limbs seizures, total body seizures, tonic seizures, and spin and jump.

- The administration of flumazenil significantly inhibited $S$. bachtiarica essential oil-induced effects and increased the head and upper limbs seizures, tonic seizures, and jumping.

\section{Plain Language Summary}

Epilepsy is one of the most common disorders of the central nervous system, so that one in every 100 people is suffering from epilepsy globally. Despite the development of antiepileptic drugs, novel strategies are sought out because of drug resistance and the side effects resulting from these drugs at high concentrations. Researchers have focused on plants for certain reasons such as availability, the history of long-term use, being nature-based, and relative safety. In the current study, the effect of the pretreatment with $S$. bachtiarica essential oil in preventing seizure was studied in the pentylenetetrazol-kindled mice. The injection of 50 and $100 \mathrm{mg} / \mathrm{kg}$ of $S$. bachtiarica essential oil caused a significant increase in latency to the first seizure and survival duration, and a significant decrease in the frequency of the head and upper limbs seizures, tonic seizures, and spin and jump in the pentylenetetrazol-receiving mice.

\section{Introduction}

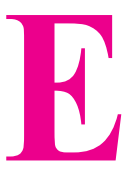

pilepsy is the second commonest neurological disorder after stroke. Nearly $1 \%$ of the global population ( 65 million) have epilepsy, and approximately $80 \%$ of the people with epilepsy live in developing countries (Karimi, Naseri, Sayyah, Kamalinejad, \& Amiri 2014).

$\gamma$-Aminobutyric acid (GABA) is an inhibitory neurotransmitter in the brain that effectively blocks the transmission of neural signals in the brain. Excessive reduction in GABA causes certain conditions in which a stimulatory neurotransmitter seems to be continuously firing and functioning. In such condition, epilepsy may occur. The drugs that cause an increase in synaptic GABA levels through inhibiting GABA catabolism or increasing GABA reabsorption, including antiepileptic drugs, are considered effective in controlling epilepsy. Benzodiazepines (e.g., diazepam) are a group of these drugs that increase the binding of the GABA to its receptors and, therefore, the frequency of chloride channels opening. A number of the inhibitors of GABA synthesis, such as thiosemicarbazide-4, isoniazid, deoxypyridoxine, and L-allylglycine, can cause a seizure (Treiman, 2001). As the most important inhibitory neurotransmitter, GABA interacts with two types of receptors, GABAA and GABAB. GABAA receptors are located postsynaptically, and GABAB ones are lo- cated presynaptically and cause modulation of synaptic release. In the adult brain, the GABAA receptors are permeable to chloride ions. Following activation, the permeation of the chloride ion causes membrane hyperpolarization and action potential inhibition. Therefore, the compounds that serve as the GABAA receptors, such as barbiturates and benzodiazepines, can effectively suppress seizures. The GABAB receptors are associated with the subsequent signaling and weakens the release of neurotransmitters according to their presynaptic positions (Gey, Gernert, \& Löscher, 2016).

Mitochondrial dysfunction due to reactive oxygen species (ROS) toxicity often occurs after a seizure. Epileptic seizures let calcium flow into the cell through N-methylD-aspartate (NMDA)-dependent ion channels. Increased intracellular ions cause a cascade of biochemical events. High levels of intracellular calcium are associated with increased production of ROS. However, ROS are inactivated by enzymatic antioxidants such as superoxide dismutase (SOD), catalase, glutathione peroxidase, glutathione reductase, and peroxiredoxins, as well as nonenzymatic antioxidants such as vitamin $\mathrm{C}$, vitamin $\mathrm{E}$, and glutathione (Kim et al. 2004). Studies have indicated that plant-based antioxidants are useful in decreasing the severity of any damage due to epileptic seizures (Gupta, Kumar, \& Srivastava, 2003). 
Satureja bachtiarica species grows widely in Iran and have been identified in the western, central, and southwestern provinces of this country (Ahmadi, et al. 2009).

In traditional medicine, $S$. bachtiarica is considered to have a relatively warm and dry nature. It is anti-flatulent and appetizing and contributes to improving sexual prowess. S. bachtiarica is used for relieving pain, and if consumed with fig juice, it is useful for treating cough, dyspnea, and brilliant facial paint. S. bachtiarica is highly useful for treating diarrhea. Its compress with olive oil is suitable for different pains due to abdominal torsion. $S$. bachtiarica, as with thyme, can be used to remove weakness and stomach cramps. Moreover, this plant can treat indigestion, intestinal fermentation, and bloating (Memarzadeh, Pirbalouti, \& AdibNejad 2015).

In a study, the essential oils of $S$. bachtiarica aerial parts were extracted by steam distillation, and their active compounds were identified by gas chromatographymass spectrometry. Out of the 26 identified compounds, thymol (44.5\%), $\gamma$-terpinene (23.9\%), p-cymene (7.3\%), beta-caryophyllene $(5.3 \%)$, and borneol $(4.2 \%)$ were found to be the main compounds (Sefidkon, Jamzad,\& Barazandeh, 2005). Sefidkon, Sadeghzadeh, Teymouri, Asgari, \& Ahmadi (2007) reported that the essential oil of pre-flowering S. bachtiarica contained $20 \%$ carvacrol and $19 \%$ thymol, and that of flowering S. bachtiarica contained approximately $26 \%$ carvacrol and 5\% thymol. They also reported that $S$. bachtiarica essential oil with $32 \mu \mathrm{g} / \mathrm{mL}$ IC50 had potential antioxidant effects in inhibiting 1,1-diphenyl-2-picrylhydrazyl (DPPH) radicals.

Nowadays, despite many advances in treating epileptic disorders, millions of people still have uncontrolled epilepsy resistant to common antiepileptic drugs such that one of every three patients does not respond appropriately to these drugs. In addition, about one-third of the patients who have recovered from epilepsy experience recurrent epilepsy after discontinuation of the drug. The complications due to antiepileptic drug toxicity lead to restricted use and not achieving the desired therapeutic effect. It is, therefore, essential to seek out appropriate drugs for epilepsy with comparatively fewer side effects. As a result, it is also necessary to consider traditional medicine and medicinal plants to achieve safe drugs with minimal side effects. S. bachtiarica has many therapeutic applications in traditional medicine. No scientific report was presented on the antiepileptic activity of $S$. bachtiarica essential oil. Hence, the present study was designed to validate the effect of S. bachtiarica essential oil in epilepsy.

\section{Materials and Methods}

\section{Preparation of S. bachtiarica essential oil}

S. bachtiarica was purchased from the groceries across Shahrekord City, Iran, and authenticated by Dr. Gooini (Botanical Survey of Iran). The essential oil was extracted by distillation using the Clevenger apparatus. For this purpose, 50g pulverized S. bachtiarica, along with 500 $\mathrm{mL}$ water was poured into the distilling flask and then heated to reach a distillation rate of $2-3 \mathrm{~mL} / \mathrm{min}$. After $4 \mathrm{~h}$, the essential oil was collected and mixed with anhydrous sodium sulfate for $24 \mathrm{~h}$ to remove water content. The essential oil was stored at $-20^{\circ} \mathrm{C}$.

\section{Determining antioxidant capacity using DPPH radicals}

First, different concentrations of $S$. bachtiarica essential oil were prepared. Also, DPPH in $0.1 \mathrm{mM}$ concentration (in methanol) was prepared. Then, $2 \mathrm{~mL}$ DPPH was added to $2 \mathrm{~mL}$ of $S$. bachtiarica essential oil prepared in different concentrations and left in the dark for $15 \mathrm{~min}$. The tube containing $2 \mathrm{~mL}$ methanol and $2 \mathrm{~mL}$ DPPH was prepared near the samples. After $15 \mathrm{~min}$, the spectrophotometer wavelength was set at 0 using blank, and then absorbance was read at $517 \mathrm{~nm}$ wavelength. The inhibition percentage of the DPPH radicals was calculated by the following Equation 1:

\section{1. $I=100 \times($ Acontrol-Asample $) /$ Acontrol}

The concentration of the essential oil in which $50 \%$ of the DPPH radicals were neutralized (IC50) was derived by plotting the graph. In this graph, the Y-axis represents inhibition percentage, and $\mathrm{X}$-axis represents extract concentration Aliabadi et al. (2016).

\section{Study animals}

We used Albino NMRI male mice weighing 20-25g. The animals were maintained under standard laboratory conditions at a temperature of $24^{\circ} \mathrm{C} \pm 2^{\circ} \mathrm{C}$ and relative humidity (30\%-70\%) with a $12: 12 \mathrm{~h}$ light: dark cycle throughout the experiment. The animals were fed with a standard pellet diet and had free access to water. The animals were transfered to the laboratory one hour prior to the experiment.

\section{Study drugs and chemicals}

All solvents, chemicals, and materials for extraction were purchased from Sigma Aldrich. Diazepam and flumazenil were product of Daru Pakhsh, Iran. All other compounds for animal experiments were obtained from Sigma-Aldrich Chemical Company. 


\section{Experimental design and animal grouping}

Group 1 (pentylenetetrazol [PTZ] group): IP received vehicle (normal saline+Tween-80) and $30 \mathrm{~min}$ later, PTZ (30 mg/kg).

Groups 2 and 3 (bachtiarica essential oil [SB-EO] groups): IP received 50 and $100 \mathrm{mg} / \mathrm{kg} \mathrm{SB}$ essential oil, respectively approximately $30 \mathrm{~min}$ before receiving PTZ.

Group 4 (diazepam group): IP received $20 \mathrm{mg}$ / kg diazepam (a GABA receptor antagonist) approximately 30min before receiving PTZ (Bakhtiarpoor \& Setorki, 2018).

Group 5 (flumazenil group): Received flumazenil (Daru Pakhsh, Iran, a selective antagonist of benzodiazepine GABAA receptors) $(10 \mathrm{mg} / \mathrm{kg}) 10 \mathrm{~min}$ before IP injection of $100 \mathrm{mg} / \mathrm{kg} \mathrm{S}$. bachtiarica essential oil, and PTZ 30min after injection of $S$. bachtiarica essential oil.

In this study, $35 \mathrm{mg} / \mathrm{kg}$ PTZ was injected IP every other day (once every $48 \mathrm{~h}$ ). The mice were injected with 50 and $100 \mathrm{mg} / \mathrm{kg}$ S. bachtiarica essential oil every day for 10 days, and on the $10^{\text {th }}$ day, $30 \mathrm{~min}$ after injection of S. bachtiarica essential oil, normal saline, and diazepam, the mice were administered with $60 \mathrm{mg} / \mathrm{kg}$ body weight (BW) PTZ, and the severity and rate of seizure were recorded and analyzed for $30 \mathrm{~min}$ by filming. Diazepam and flumazenil were injected only once and on the last day.

\section{Induction of seizures by PTZ}

After the last injection of PTZ (Sigma Aldrich), latency to the first seizure, seizure severity (score), the completion time of each seizure (attack duration), and mortality rate in different groups were measured and compared. Scoring was as follows:

0 : Normal behavior: In adult rats, it involves initial orientation lasting 2 to $3 \mathrm{~min}$.

\section{1: Head Tic}

2: Repeated seizures of the head and jerk of the anterior limb

\section{3: The seizure of the entire body and standing up}

4: Tonic seizures: while the animal was on its belly (without the loss of balance)

5: Repeated spin and jump
6: Death (Solati, et al. 2019)

\subsection{Data Analysis}

Data analysis was conducted by SPSS software, version 16. One-way analysis of variance and Tukey's test were used to investigate the significance of differences among different treatments and respective mean values, respectively. Data were expressed as $\mathrm{Mean} \pm \mathrm{SD}$, and $\mathrm{P}<0.05$ was considered the significance level.

\section{Results \\ S. bachtiarica essential oil inhibitory effect on DPPH radicals}

According to the results, $50 \%$ of the DPPH radicals were inhibited by $0.095 \mathrm{mg} / \mathrm{mL} S$. bachtiarica essential oil (IC50 $=0.095 \mathrm{mg} / \mathrm{mL}$ ) (Figure 1).

\section{Latency to the first seizure}

Figure 2 illustrates the effect of $S$. bachtiarica essential oil on latency to the first seizure in the mice receiving PTZ, 50 and $100 \mathrm{mg} / \mathrm{kg}$ S. bachtiarica essential oil, and flumazenil $+100 \mathrm{mg} / \mathrm{kg}$ S. bachtiarica essential oil. As illustrated, 50 and $100 \mathrm{mg} / \mathrm{kg} \mathrm{S}$. bachtiarica essential oil caused a significant increase in latency to the first seizure in the PTZ-receiving mice $(\mathrm{P}<0.05)$. The latency to the first seizure was significantly longer in the diazepamreceiving group than the groups receiving $S$. bachtiarica essential oil+PTZ $(\mathrm{P}<0.001)$. The latency to the first seizure was not significantly different between the flumazenil $(10 \mathrm{mg} / \mathrm{kg} \mathrm{IP})+100 \mathrm{mg} / \mathrm{kg}$ S. bachtiarica essential oilreceiving group and the groups receiving $S$. bachtiarica essential oil $+\mathrm{PTZ}(\mathrm{P}>0.05)$.

Figure 3 illustrates the effect of $S$. bachtiarica essential oil on survival duration in the mice receiving PTZ, 50 and $100 \mathrm{mg} / \mathrm{kg}$ S. bachtiarica essential oil, and flumazenil $+100 \mathrm{mg} / \mathrm{kg}$ S. bachtiarica essential oil. As illustrated, 50 and $100 \mathrm{mg} / \mathrm{kg} \mathrm{S}$. bachtiarica essential oil caused a significant increase in survival duration in the PTZ-receiving mice $(\mathrm{P}<0.01$ and $\mathrm{P}<0.001$, respectively). Survival duration decreased in the flumazenil $+100 \mathrm{mg} / \mathrm{kg}$ $S$. bachtiarica essential oil-receiving group compared to the groups receiving $100 \mathrm{mg} / \mathrm{kg} \mathrm{S}$. bachtiarica essential oil yet insignificantly. In the diazepam group, no mouse died, and therefore, survival duration was not measured.

\section{Head tic frequency}

Figure 4 illustrates the effect of $S$. bachtiarica essential oil on the head tic frequency in the mice receiving 


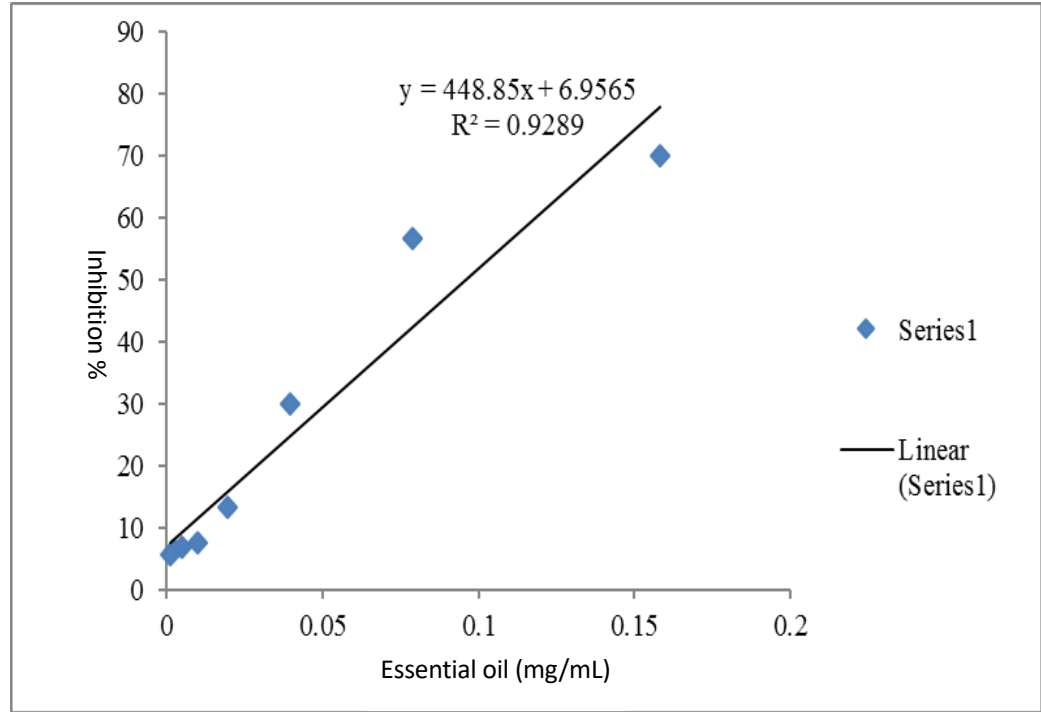

Figure 1. S. bachtiarica inhibitory effect on DPPH radicals

PTZ, 50 and $100 \mathrm{mg} / \mathrm{kg} \mathrm{S.} \mathrm{bachtiarica} \mathrm{essential} \mathrm{oil,} \mathrm{and}$ flumazenil+100 mg/kg S. bachtiarica essential oil. As illustrated, $100 \mathrm{mg} / \mathrm{kg}$, unlike $50 \mathrm{mg} / \mathrm{kg}$, S. bachtiarica essential oil caused a significant decrease in the head tic frequency in the PTZ-receiving mice $(\mathrm{P}<0.01)$. The head tic frequency was significantly lower in the diazepam-receiving group than in the groups receiving $S$. bachtiarica essential oil and PTZ $(\mathrm{P}<0.001)$. The head tic frequency was significantly higher in flumazenil $+100 \mathrm{mg} / \mathrm{kg} S$. bachtiarica essential oil than in the group receiving 100 $\mathrm{mg} / \mathrm{kg}$ S. bachtiarica essential oil $(\mathrm{P}<0.05)$.

Total frequency of the head and upper limbs seizures

AS seen, 50 and $100 \mathrm{mg} / \mathrm{kg}$ S. bachtiarica essential oil caused a significant decrease in the total frequency of the head and upper limbs seizures in the PTZ-receiving mice $(\mathrm{P}<0.05)$. The total frequency of the head and upper limbs seizures was significantly lower in the diazepam-receiving group than $S$. bachtiarica essential oil+PTZ-receiving group $(\mathrm{P}<0.001)$. The total frequency of the head and upper limbs seizures was higher in the flumazenil $+100 \mathrm{mg} / \mathrm{kg} S$. bachtiarica essential oil than in the groups receiving 50 and $100 \mathrm{mg} / \mathrm{kg} \mathrm{S.} \mathrm{bachtiarica} \mathrm{es-}$ sential oil $(\mathrm{P}<0.05)$ (Figure 5).

\section{Frequency of Tonic seizures}

Figure 6 illustrates the effect of $S$. bachtiarica essential oil on the frequency of tonic seizures in the mice receiving PTZ, 50 and $100 \mathrm{mg} / \mathrm{kg} \mathrm{S.} \mathrm{bachtiarica} \mathrm{essential} \mathrm{oil,}$ and flumazenil $+100 \mathrm{mg} / \mathrm{kg} S$. bachtiarica essential oil. As illustrated, 50 and $100 \mathrm{mg} / \mathrm{kg} \mathrm{S.} \mathrm{bachtiarica} \mathrm{essen-}$ tial oil caused a significant decrease in the frequency of tonic seizures in the mice receiving PTZ $(\mathrm{P}<0.001)$. The frequency of tonic seizures was significantly lower in the diazepam-receiving group than in the groups receiving 50 and $100 \mathrm{mg} / \mathrm{kg}$ S. bachtiarica essential oil+PTZ $(\mathrm{P}<0.001)$. The frequency of tonic seizures was significantly higher in the flumazenil $+100 \mathrm{mg} / \mathrm{kg} \mathrm{S}$. bachtiarica essential oil than the groups receiving 50 and $100 \mathrm{mg} / \mathrm{kg}$ $S$. bachtiarica essential oil $(\mathrm{P}<0.001)$.

Frequency of repeated spin and jump

Figure 7 illustrates the effect of $S$. bachtiarica essential oil on the frequency of repeated spin and jump in the mice. As illustrated, 50 and $100 \mathrm{mg} / \mathrm{kg} \mathrm{S.} \mathrm{bachtiarica} \mathrm{es-}$ sential oil caused a significant decrease in the frequency of repeated spin and jump in the PTZ-receiving mice $(\mathrm{P}<0.001)$. The frequency of repeated spin and jump was significantly lower in the diazepam-receiving group than in the groups receiving 50 and $100 \mathrm{mg} / \mathrm{kg} \mathrm{S}$. bachtiarica essential oil $+\mathrm{PTZ}(\mathrm{P}<0.001)$.

\section{Survival rate}

Figure 8 illustrates the effect of $S$. bachtiarica essential oil on the survival rate of the mice. As illustrated, the survival rate was $50 \%$ in the PTZ-receiving mice. In the group receiving PTZ $+50 \mathrm{mg} / \mathrm{kg} \mathrm{S}$. bachtiarica essential oil, the survival rate was $75 \%$. In the group receiving PTZ $+100 \mathrm{mg} / \mathrm{kg} \mathrm{S}$. bachtiarica essential oil, the survival rate was $91 \%$. In the group receiving flumazenil $+100 \mathrm{mg} / \mathrm{kg} \mathrm{S}$. bachtiarica essential oil, the survival rate was $50 \%$, and in the diazepam-receiving group, the survival rate was $100 \%$. 


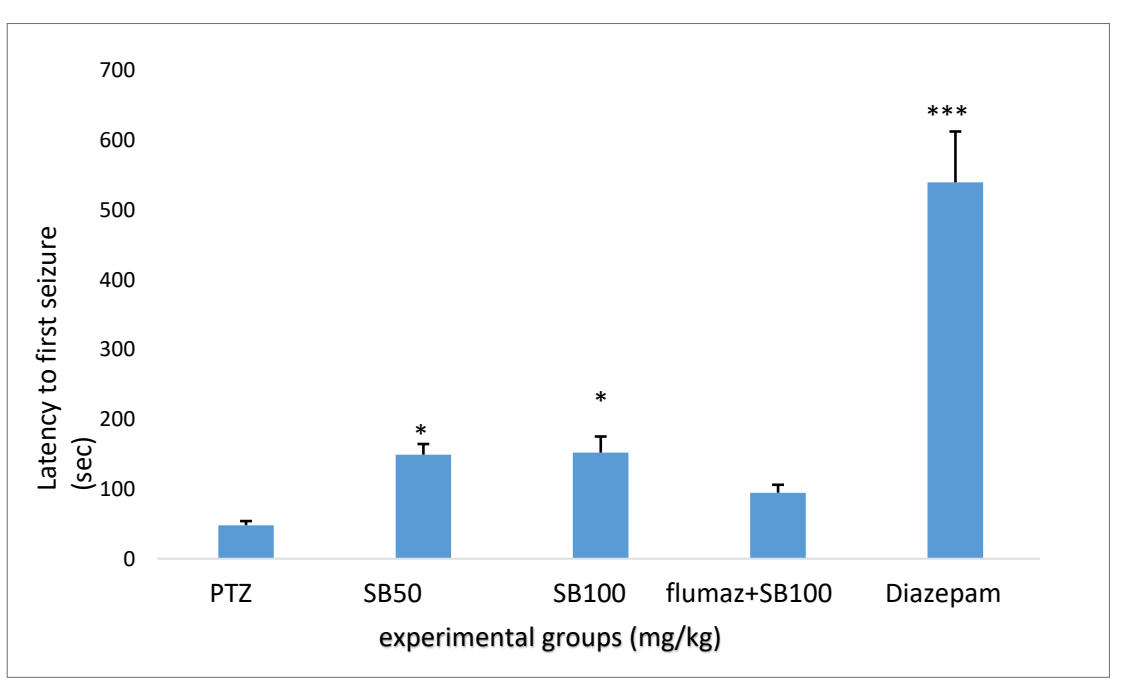

Figure 2. Effect of $S$. bachtiarica essential oil on latency to the first seizure in mice

NEUR SCIENCE

***Significant difference compared to the PTZ group $(\mathrm{P}<0.001)$; *Significant difference compared to the PTZ group $(\mathrm{P}<0.05)$.

SB: Satureja bachtiarica; PTZ: pentylenetetrazol; Flumaz: Flumazenil.

\section{Discussion}

In the current study, the effect of the pretreatment with $S$. bachtiarica essential oil in preventing seizure was studied in the PTZ-kindled mice. The injection of 50 and $100 \mathrm{mg} / \mathrm{kg}$ S. bachtiarica essential oil caused a significant increase in latency to the first seizure and survival duration, and a significant decrease in the frequency of the head and upper limbs seizures, tonic seizures, and spin and jump in the PTZ-receiving mice

However, S. bacteria essential oil at $50 \mathrm{mg} / \mathrm{kg}$ had no significant effect on the frequency of the head tics. Flu- mazenil significantly inhibited the effects of this essential oil and caused a significant increase in the frequency of head and upper limbs seizures, tonic seizures, and spin and jump. Besides that, flumazenil decreased latency to the first seizure and survival duration insignificantly.

Assaei, Bashiri, \& Pajuhi (2012) reported that $S$. khuzestanica essential oil, at 40, 80, and $120 \mathrm{mg} / \mathrm{kg}$ increased the latency to the first seizure and decreased seizure severity and durability in mice. Different studies to identify the chemical compounds of $S$. bachtiarica essential oil demonstrated that thymol and carvacrol are two main compounds of this essential oil (Sefidkon et al.,

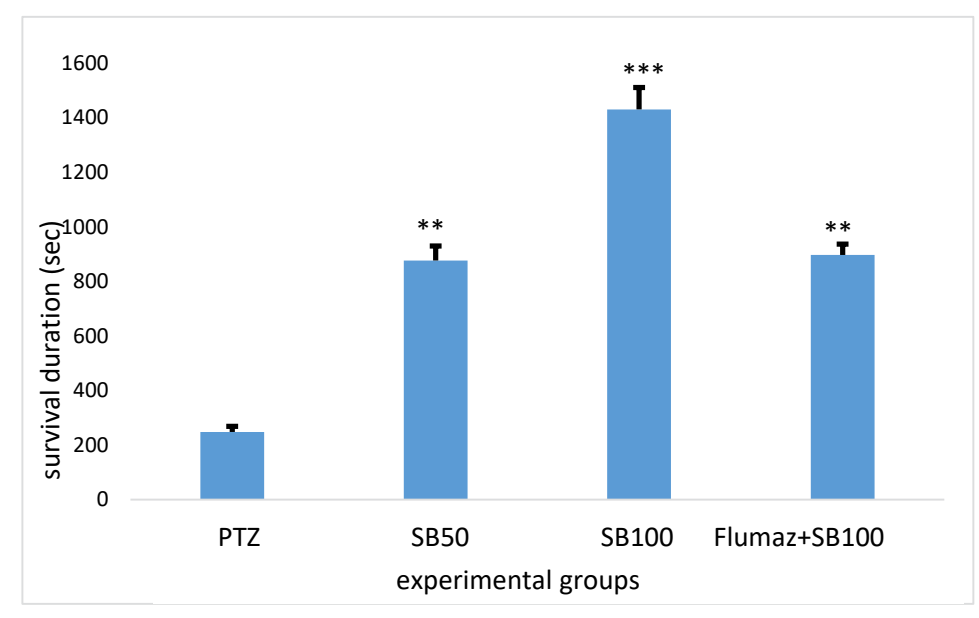

Figure 3. Effect of satureja bachtiarica essential oil on survival duration in mice

*** Significant difference compared to the PTZ group $(\mathrm{P}<0.001)$; ** Significant difference compared to the PTZ group $(\mathrm{P}<0.01)$.

SB: Satureja bachtiarica; PTZ: pentylenetetrazol; Flumaz: Flumazenil. 


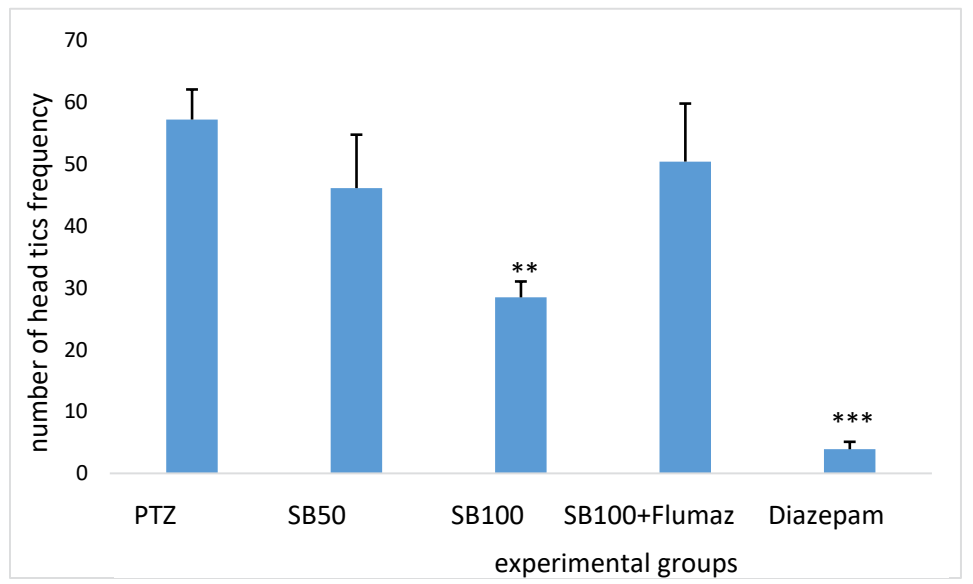

Figure 4. Effect of satureja bachtiarica essential oil on the head tic frequency in mice

***Significant difference compared to the PTZ group $(\mathrm{P}<0.001)$; **Significant difference compared to the PTZ group $(\mathrm{P}<0.01)$.

SB: Satureja bachtiarica; PTZ: pentylenetetrazol; Flumaz: Flumazenil.

2005; Memarzadeh, et al. 2015). Aliabadi et al. (2016) reported that IP injection of thymol decreased the severity and latency of the first seizure in mice. QuintansJunior et al. (2010) study showed that carvacrol caused PTZ-induced seizure to relieve.

As mentioned before, thymol and carvacrol are the two main compounds in S. bachtiarica essential oil. García, Bujons, Vale, \& Suñol's (2006) study on the thymol effect on GABAA receptors in cortical neuron culture showed that thymol caused an increase in chloride ion transport from the GABAA receptors, which significantly decreased in the presence of the GABAA receptors. Thymol caused an increase in the combined appetite of GABA agonists for the GABAA receptors, including muscimol and flunitraz- epam. Melo et al. showed that carvacrol exerted anti-anxiety effects in a mice model. In Melo et al. study, flumazenil significantly inhibited carvacrol and diazepam-induced anti-anxiety effects. They argued that carvacrol anti-anxiety effects were due to the GABAA receptors (Kalueff, Lehtimaki, Ylinen, Honkaniemi, \& Peltola, 2004).

In the present study, flumazenil significantly inhibited the effects of $S$. bachtiarica essential oil, and it can therefore be argued that the anticonvulsant effects of this plant are exerted via the GABAergic system.

It is argued that acetylcholine and its nicotinic receptors may play a role in stimulating and maintaining seizures. Inducing epilepsy through injecting lithium, pilocarpine, and

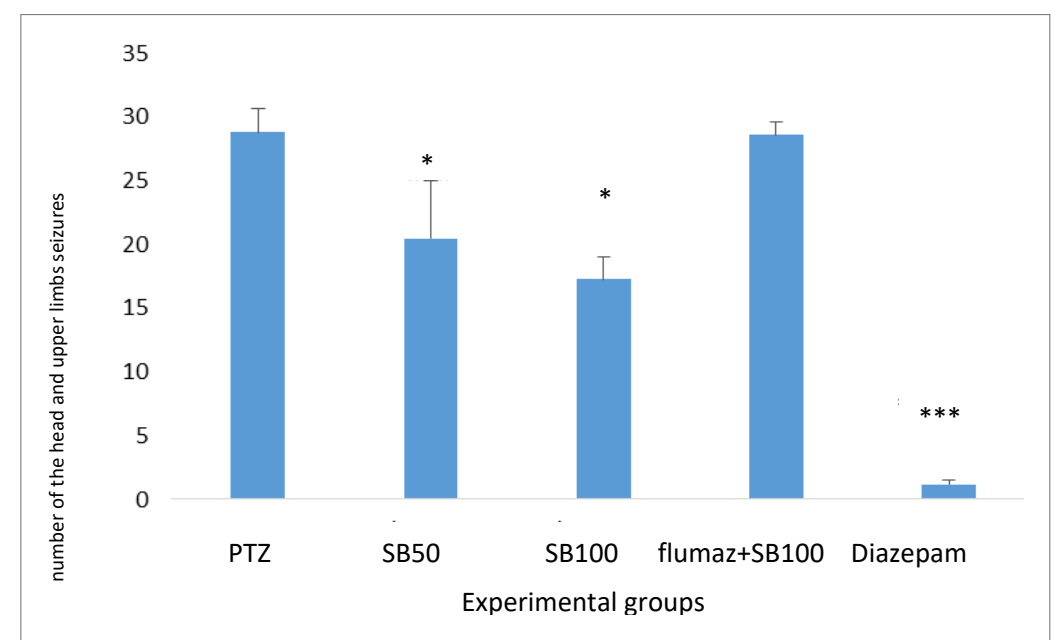

NEUR SCIENCE

Figure 5. Effect of satureja bachtiarica essential oil on the total frequency of the head and upper limbs seizures in mice

***Significant difference compared to the PTZ group $(\mathrm{P}<0.001)$; *Significant difference compared to the PTZ group $(\mathrm{P}<0.05)$.

SB: Satureja bachtiarica; PTZ: pentylenetetrazol; Flumaz: Flumazenil. 


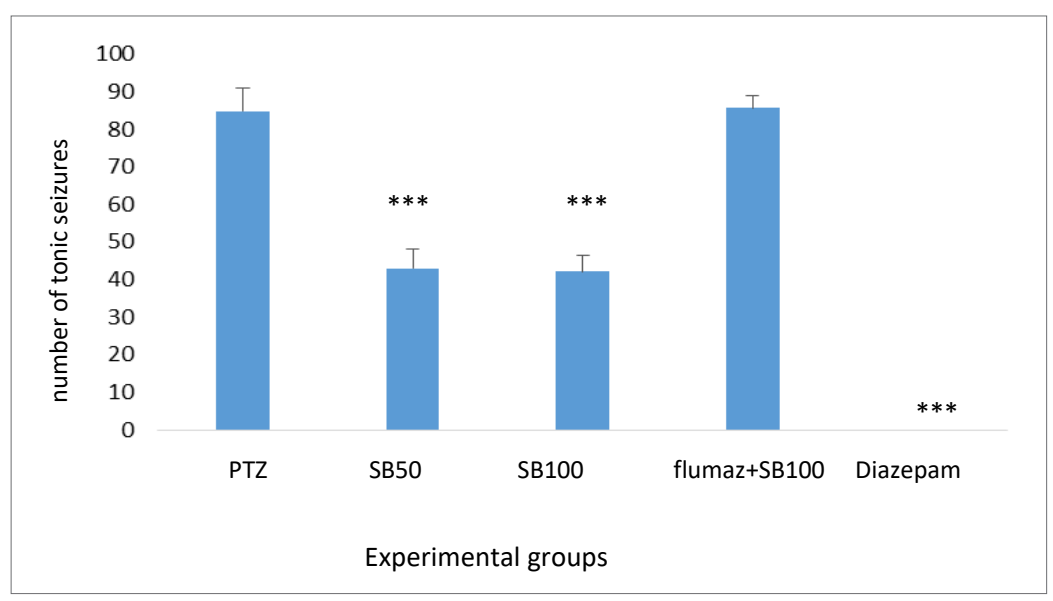

Figure 6. Effect of satureja bachtiarica essential oil on the total frequency of tonic seizures in mice

***Significant difference compared to the PTZ group $(\mathrm{P}<0.001)$.

SB: Satureja bachtiarica; PTZ: pentylenetetrazol; Flumaz: Flumazenil.

kainate causes a significant increase in the acetylcholine levels in the brain and hippocampal membrane. In addition, treatment with the NMDA receptor antagonists causes a significant decrease in brain acetylcholine levels (Steinlein, 2002). Recently, the role of certain mutations in the subunits of the nicotinic acetylcholine receptors has been confirmed in the incidence of certain types of epilepsy. Steinlein et al. (1995) study showed that the point mutations in the $\alpha 4$ subunits of the acetylcholine receptors were associated with autosomal dominant nocturnal frontal lobe epilepsy. Potier \& Psarropoulou (2001) study indicated that adding acetylcholinesterase inhibitor caused a significant increase in the incidence rate of spontaneous seizure. The muscarinic antagonists inhibited all these effects. They argued that inhib- iting cholinergic activity caused seizure termination while stimulating this activity induced seizure.

The anticholinergic effects of thymol and carvacrol have already been demonstrated. Jukic et al. (2007) reported that carvacrol-induced acetylcholinesterase inhibition was 10 times more potent than thymolinduced inhibition of this enzyme, while these two compounds have similar chemical structures. Hejazian et al. (2014) observed that S. bachtiarica essential oil relieved acetylcholine-induced contractions in guinea pig ileum. It seems that $S$. bachtiarica essential oil inhibits PTZ-induced seizures by decreasing the brain

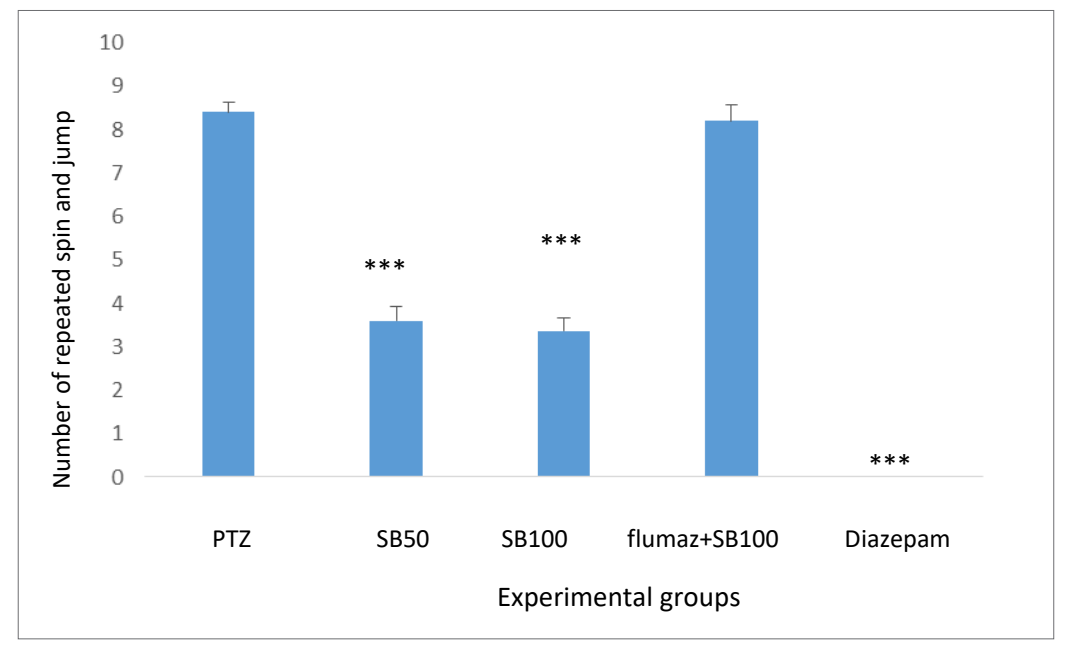

Figure 7. Effect of satureja bachtiarica essential oil on the frequency of repeated spin and jump in mice

***Significant difference compared to PTZ group $(\mathrm{P}<0.001)$.

SB: Satureja bachtiarica; PTZ: pentylenetetrazol; Flumaz: Flumazenil. 


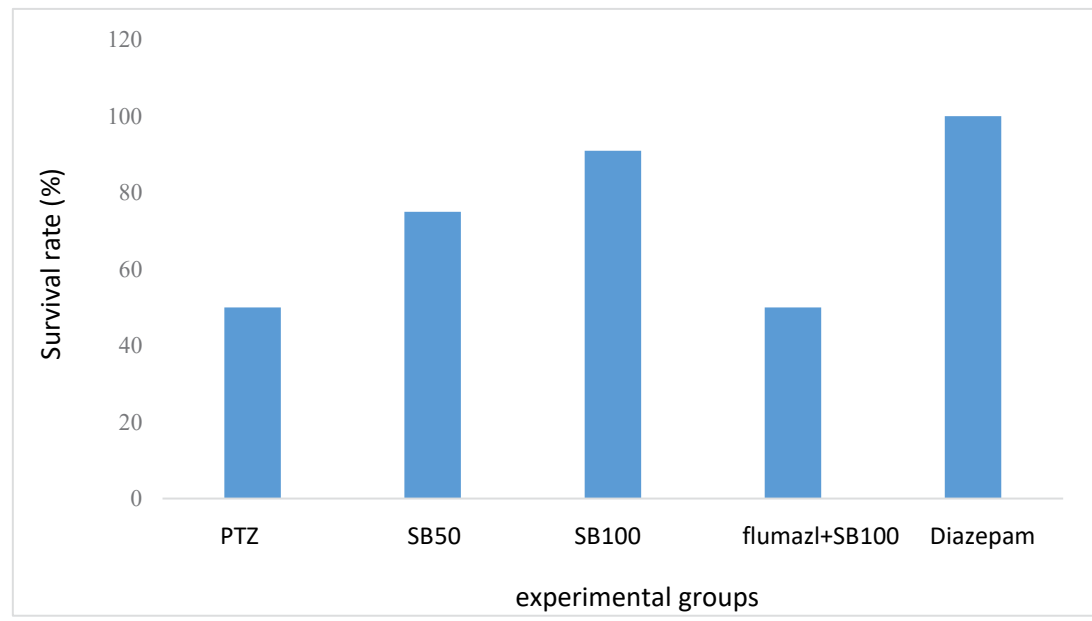

Figure 8. Effect of satureja bachtiarica essential oil on the survival rate of mice

SB: Satureja bachtiarica; PTZ: pentylenetetrazol; Flumaz: Flumazenil.

acetylcholine levels; however, this argument deserves further investigation.

Certain anticonvulsants act through blocking calcium channels. Suzuki et al. (1992) reported that zonisamide decreased calcium ion flow into T-type calcium channels but did not cause any significant change in the Ltype calcium channels. Fletcher et al. (1996) reported that $\alpha 1 \mathrm{~A}$ calcium channels in the brain of the mouse with epilepsy were dysfunctional. Jouvenceau et al. (2001) argued that the absence of epilepsy was associated with dysfunction of the P/Q-type voltage-gated calcium channel. Because thymol can decrease the ion calcium flow into the skeletal muscle calcium channels (Szentandrássy, Szentesi, Magyar, Nánási, \& Csernoch 2003), the anticonvulsant effects of $S$. bachtiarica essential oil can be attributed to the effects of its active compounds on the ions flow into the calcium channels; however, this should be studied more vigorously.

Oxidative stress causes cell dysfunction and several cell damage. It has been reported that seizure is associated with the hemostatic imbalance between antioxidants and oxidants (Kim et al. 2004). Oxidative stress contributes significantly to brain injury and neuronal death due to seizure (Gupta, et al. 2003). Animal studies have indicated that epileptic attacks cause the production of free radicals and oxidative damage to proteins, lipids, and cell DNA. Excessive production of mitochondrial superoxide, inactivation of iron and sulfur-dependent enzymes such as aconitase, and iron-induced toxicity may contribute to the oxidative stress of the neurons after epileptic attacks (Kim et al. 2004). In a study on 50 patients with epilepsy, lipids peroxidation and the percentage of erythrocytes hemodialysis were significantly higher in these patients than in healthy people. Besides that, plasma ceruloplasmin concentration was significantly higher in patients with epilepsy.

The levels of glutathione reductase and vitamins $\mathrm{A}$, $\mathrm{C}$, and $\mathrm{E}$ in the erythrocytes were significantly lower in patients with epilepsy than in healthy people (Sudha, Rao, \& Rao, 2001). Because the antioxidant effects of S. bachtiarica essential oil (Hashemi, Niakousari, \& Saharkhiz, 2011) and its active compounds such as thymol (Youdim \& Deans 2000) and carvacrol (Aeschbach, et al. 1994) have been confirmed, it can be argued that the protective effects of this essential oil against PTZinduced seizure are due to its antioxidant effects.

In vitro studies have indicated that inducing epilepsy in rodents causes a significant increase in the inflammatory mediators in regions involved in epilepsy, and anti-inflammatory drugs decrease the severity of certain types of epilepsy in animal models (Kalueff, et al., 2004). High expression of inflammatory cytokines such as tumor necrosis factor-alpha and interleukin-6 in the astrocytes decreases seizure threshold and spontaneous seizure frequency (Virta, Hurme, \& Helminen, 2002). Deng et al. reported that thymol significantly relieved depression due to irreversible chronic stress model (Deng, et al. 2015). The anti-inflammatory effects of carvacrol and thymol on carrageenan-induced ear edema and inflammation in rats have also been demonstrated (Fachini-Queiroz, et al. 2012).

Aliabadi et al. (2016) studied the effect of pretreatment with thymol at different concentrations in the PTZinduced epilepsy model. PTZ caused the generalized seizure and was associated with increased lipids peroxidation and decreased SOD activity. In addition, consecu- 
tive PTZ injections caused a significant increase in the levels of the inflammatory markers in the mouse hippocampus. In that study, intraperitoneal injection of thymol caused a decrease in the severity of seizure and latency to the first seizure. Thymol also decreased malondialdehyde levels in the brain and inflammatory markers and increased SOD activity.

The present study demonstrated that $S$. bachtiarica essential oil significantly decreased seizure severity, latency to the first seizure, and survival duration. The anticonvulsant effects of this essential oil are due to its effect on the GABAA receptors such that flumazenil inhibited these effects. The anticonvulsant effects of $S$. bachtiarica essential oil may be related to its active compounds, such as thymol and carvacrol. Besides that, other mechanisms, such as preventing oxidative stress and decreasing the levels of acetylcholine in the brain and inflammatory mediators, can contribute to the anticonvulsant activity of this essential oil. It is recommended to investigate such possibilities.

\section{Ethical Considerations}

\section{Compliance with ethical guidelines}

Shahrekord University of Medical Science Research Ethics Committee reviewed all procedures and experiments as the local referral Biomedical Committee for Research Ethics. Protocols and guidelines were carried out following the National Institutes of Health (NIH) for the care and use of experimental animals. Supervision of animal protocols was carried out according to the research design.

\section{Funding}

This study was funded by Shahrekord University of Medical Science Research and Technology Vice Chancellor Grant (No: 2611-75-01-1394).

\section{Authors' contributions}

Conceptualization and Supervision: Zahra Rabiei and Mahmoud Rafieian-Kopaei; Methodology: Manouchehr Shirchi; Investigation, Writing - original draft, and Writing review \& editing: All authors; Data collection: Zahra Rabiei, Manouchehr Shirchi, and Samira Asgharzade; Data analysis: Mahmoud Rafieian-Kopaei and Zahra Rabiei; Funding acquisition and Resources: Zahra Rabiei, Manouchehr Shirchi, Samira Asgharzade, and Mahmoud Rafieian-Kopaei.

\section{Conflict of interest}

The authors declared no conflict of interest.

\section{Acknowledgments}

This research was financially supported by the Research Deputy of Shahrekord University of Medical Science, Shahrekord City, Iran (No: 2611-75-01-1394).

\section{References}

Aeschbach, R., J., Löliger, B., Scott, A., Murcia, J., Butler, B., Halliwell, B., et al. (1994). Antioxidant actions of thymol, carvacrol, 6-gingerol, zingerone and hydroxytyrosol. Food and Chemical Toxicology, 32(1), 31-36. [DOI:10.1016/0278-6915(84)90033-4]

Ahmadi, S., F., Sefidkon, F., Babakhanlou, P., Asgari, F., Khademi, K., \& Karimifar, M. A. (2009). Comparing essential oil composition of Satureja bachtiarica Bunge before and full flowering stages in field and provenance. Iranian Journal of Medicinal and Aromatic Plants, 25(2), 159-169. [Link]

Aliabadi, A., Izadi, M., Rezvani, M. E., Esmaeili-dehaj, M. (2016). Effects of thymol on serum biochemical and antioxidant indices in kindled rats. International Journal of Medical Laboratory, 3(1), 43-49. [Link]

Assaei, R., Bashiri, M., \& Pajuhi, N. (2012). The effect of Satureja Khuzestanica essential oil (SKEO) on convulsion induced by nicotine in male mice. Yafteh, 14(2), 23-9. [Link]

Bakhtiarpoor, M. \& Setorki, M. (2018). Effects of essential oil of Satureja bachtiarica Bunge in a rat model of reserpine-induced depression. Iranian Journal of Medical Sciences, 43(4), 409. [PMID] [PMCID]

Deng, X. Y., Li, H. Y., Chen, J. J., Li, R. P., Qu, R., Fu, Q., et al. (2015) Thymol produces an antidepressant-like effect in a chronic unpredictable mild stress model of depression in mice. Behavioural Brain Research, 291,12-19. [DOI:10.1016/j.bbr.2015.04.052] [PMID]

Fachini-Queiroz, F. C., Kummer, R., Estevão-Silva, C. F., Carvalho, M. D., Cunha, J. M., Grespan, R., et al. (2012). Effects of thymol and carvacrol, constituents of Thymus vulgaris L. essential oil, on the inflammatory response. Evidence-based complementary and alternative medicine : eCAM, 2012, 657026. [DOI:10.1155/2012/657026] [PMID] [PMCID]

Fletcher, C. F., Lutz, C. M., O'Sullivan, T. N., Shaughnessy Jr, J D., Hawkes, R., Frankel, W. N., et al. (1996). Absence epilepsy in tottering mutant mice is associated with calcium channel defects. Cell, 87(4), 607-617. [DOI:10.1016/S0092-8674(00)81381-1]

Gey, L., Gernert, M., \& Löscher, W. (2016). Continuous bilateral infusion of vigabatrin into the subthalamic nucleus: Effects on seizure threshold and GABA metabolism in two rat models. Neurobiology of Disease, 91, 194-208. [PMID] [DOI:10.1016/j.nbd.2016.03.012] 
García, D. A., Bujons, J., Vale, C., \& Suñol, C. (2006). Allosteric positive interaction of thymol with the GABAA receptor in primary cultures of mouse cortical neurons. Neuropharmacology, 50(1), 25-35. [DOI:10.1016/j.neuropharm.2005.07.009] [PMID]

Gupta, Y., Veerendra Kumar, M., \& Srivastava, A. K. (2003) Effect of Centella asiatica on pentylenetetrazole-induced kindling, cognition and oxidative stress in rats. Pharmacology Biochemistry and Behavior, 74(3), 579-585. [DOI:10.1016/ S0091-3057(02)01044-4]

Hashemi, M. B., Niakousari, M., \& Saharkhiz, M. J. (2011). Antioxidant activity of Satureja bachtiarica Bunge essential oil in rapeseed oil irradiated with UV rays. European Journal of Lipid Science and Technology, 113(9), 1132-1137. [DOI:10.1002/ejlt.201000547]

Hejazian, S., Bameri, M., Bagheri, S., \& Abbasi Sarcheshmeh A. (2014). The effect of Satureja essence on acetylcholineinduced contraction in male rat's ileum. Journal of Rafsanjan University of Medical Sciences, 13(4), 395-404. [Link]

Jouvenceau, A., Eunson, L. H., Spauschus, A., Ramesh, V., Zuberi, S. M., Kullmann, D. M., et al. (2001). Human epilepsy associated with dysfunction of the brain P/Q-type calcium channel. Lancet, 358(9284), 801-807. [DOI:10.1016/S0140-6736(01)05971-2]

Jukic, M., Politeo, O., Maksimovic, M., Milos, M., \& Milos, M. (2007). In vitro acetylcholinesterase inhibitory properties of thymol, carvacrol and their derivatives thymoquinone and thymohydroquinone. Phytotherapy Research: PTR, 21(3), 259261. [DOI:10.1002/ptr.2063] [PMID]

Kalueff, A. V., Lehtimaki, K. A., Ylinen, A., Honkaniemi, J., \& Peltola, J. (2004). Intranasal administration of human IL-6 increases the severity of chemically induced seizures in rats. Neuroscience Letters, 365(2), 106-110. [DOI:10.1016/j.neulet.2004.04.061] [PMID]

Karimi, M., Naseri, M., Sayyah, M., Kamalinejad, M., Amiri, S. (2014). Evaluation of anticonvulsive effect of methanol extract of ferula asafoetida gum in mice. Shefaye Khatam, 2(1), 46-50. [DOI:10.18869/acadpub.shefa.2.1.46]

Kim, B. H., Lee, H. G., Choia, J. K., Kim, J. I., Choi, E. K., Carp, R. I., et al. (2004). The cellular prion protein (PrPC) prevents apoptotic neuronal cell death and mitochondrial dysfunction induced by serum deprivation. Molecular Brain Research, 124 (1), 40-50. https://doi.org/10.1016/j.molbrainres.2004.02.005. [DOI:10.1016/j.molbrainres.2004.02.005] [PMID]

Memarzadeh, S. M., Pirbalouti, A. G., \& AdibNejad, M. (2015) Chemical composition and yield of essential oils from Bakhtiari savory (Satureja bachtiarica Bunge.) under different extraction methods. Industrial Crops and Products, 76, 809-816. [DOI:10.1016/j.indcrop.2015.07.068]

Potier, S., \& Psarropoulou, C. (2001). Endogenous acetylcholine facilitates epileptogenesis in immature rat neocortex. Neuroscience Letters, 302(1), 25-28. [DOI:10.1016/S0304-3940(01)01641-X]

Quintans-Júnior, L. J., Guimarães, A. G., Araújo, B. E. S., Oliveira, G. F., Santana, M. T., Moreira, F. V., et al. (2010). Carvacrol, (-)-borneol and citral reduce convulsant activity in rodents. African Journal of Biotechnology, 9(39), 6566-6572. [Link]

Sefidkon, F., Jamzad, Z., Barazandeh, M. M. (2005). Essential oil of Satureja bachtiarica Bunge, a potential source of carvacrol. Iranian Journal of Medicinal and Aromatic Plants, 20 (4), 425-439. [Link]
Sefidkon, F., Sadeghzadeh, L., Teymouri, M., Asgari, F., \& Ahmadi, S. (2007). Antimicrobial effects of the essential oils of two Satureja species (S. Khuzistanica Jamzad and S. bachtiarica Bunge) in two harvesting time. Iranian Journal of Medicinal and Aromatic Plants, 23(2), 174-182. [Link]

Solati, K., Rabiei, Z., Asgharzade, S., Amini-Khoei, H., Hassanpour, A., Abbasiyan, Z., et al. (2019). The effect of pretreatment with hydroalcoholic extract of Alpinia officinarum rhizome on seizure severity and memory impairment in pentylenetetrazol-induced kindling model of seizure in rat. AIMS Neuroscience, 6(3), 128-145. [DOI:10.3934/Neuroscience.2019.3.128] [PMID] [PMCID]

Steinlein O. K. (2002). Nicotinic acetylcholine receptors and epilepsy. Current Drug Targets. CNS and Neurological Disorders, 1(4), 443-448. [DOI:10.2174/1568007023339193] [PMID]

Steinlein, O. K., Mulley, J. C., Propping, P., Wallace, R. H., Phillips, H. A., Sutherland, G. R., et al. (1995). A missense mutation in the neuronal nicotinic acetylcholine receptor alpha 4 subunit is associated with autosomal dominant nocturnal frontal lobe epilepsy. Nature Genetics, 11(2), 201-203. [DOI:10.1038/ng1095-201] [PMID]

Sudha, K., Rao, A. V., \& Rao, A. (2001). Oxidative stress and antioxidants in epilepsy. Clinica Chimica Acta, 303(1-2), 19 24. [DOI:10.1016/S0009-8981(00)00337-5]

Suzuki, S., Kawakami, K., Nishimura, S., Watanabe, Y., Yagi, K., Scino, M., et al. (1992). Zonisamide blocks T-type calcium channel in cultured neurons of rat cerebral cortex. Epilepsy Research, 12(1), 21-27. [DOI:10.1016/0920-1211(92)90087-A]

Szentandrássy, N., Szentesi, P., Magyar, J., Nánási, P. P., \& Csernoch, L. (2003). Effect of thymol on kinetic properties of $\mathrm{Ca}$ and $\mathrm{K}$ currents in rat skeletal muscle. BMC Pharmacology, 3, 9. [DOI:10.1186/1471-2210-3-9] [PMID] [PMCID]

Treiman D. M. (2001). GABAergic mechanisms in epilepsy. Epilepsia, 42(Suppl 3), 8-12. [DOI:10.1046/j.15281157.2001.042suppl.3008.x] [PMID]

Virta, M., Hurme, M., \& Helminen, M. (2002). Increased plasma levels of pro- and anti-inflammatory cytokines in patients with febrile seizures. Epilepsia, 43(8), 920-923. [DOI:10.1046/j.1528-1157.2002.02002.x] [PMID]

Wang, Q., Li, W. X., Dai, S. X., Guo, Y. C., Han, F. F., Zheng, J. J., et al. (2017). Meta-analysis of Parkinson's disease and Alzheimer's disease revealed commonly impaired pathways and dysregulation of NRF2-dependent genes. Journal of Alzheimer's disease : JAD, 56(4), 1525-1539. [DOI: 10.3233/JAD-161032] [PMID]

Youdim, K. A., \& Deans, S. G. (2000). Effect of thyme oil and thymol dietary supplementation on the antioxidant status and fatty acid composition of the ageing rat brain. The British Journal of Nutrition, 83(1), 87-93. [DOI:10.1017/ S000711450000012X]] [PMID] 
This Page Intentionally Left Blank 